\title{
The Role of Pelvic Neurophysiology Testing in the Assessment of Patients with Voiding Dysfunction
}

\author{
Prasad Malladi $^{1} \cdot$ Sara Simeoni ${ }^{1} \cdot$ Jalesh N. Panicker $^{1}$ (I)
}

Accepted: 15 July 2020 / Published online: 9 November 2020

(C) The Author(s) 2020

\begin{abstract}
Purpose of Review The role of pelvic neurophysiology testing in the evaluation of patients with lower urinary tract (LUT) symptoms is explored in this review.

Recent Findings Different neurophysiology tests such as sphincter EMG and pudendal somatosensory evoked potentials are useful in evaluating the sacral somatic afferent and efferent innervation. S2 and S3 dermatomal evoked potentials assess individual sacral roots and are feasible to perform using standard neurophysiology machines.

Summary The innervation of the LUT has a substantial contribution from splanchnic and somatic nerves arising from the sacral segments. Pelvic neurophysiology tests, which assess somatic nerve functions, are therefore a useful tool in assessing sacral nerve functions in patients presenting with unexplained voiding dysfunction. In this review, the commonly performed neurophysiology studies that assess the S2, S3 and S4 sacral afferent and efferent pathways are outlined, and their clinical applications reviewed.
\end{abstract}

Keywords Pelvic neurophysiology $\cdot$ Dermatomal evoked potentials $\cdot$ Sacral reflex $\cdot$ Pudendal $\cdot$ Sphincter EMG $\cdot$ Lower urinary tract (LUT)

\section{Introduction}

The LUT is innervated by the somatic, sympathetic and parasympathetic nervous systems. Sacral S2-S4 somatic fibres travel through the pudendal nerve derived from the Onuf's nucleus and sensory fibres convey sensations from the perineum and external genitalia, and motor fibres innervate the external urethral and anal sphincters, bulbospongiosus and ischiocavernosus muscles.

This article is part of the Topical Collection on Voiding Dysfunction Evaluation

Prasad Malladi

a.malladi@ucl.ac.uk

Sara Simeoni

sara.simeoni@nhs.net

Jalesh N. Panicker

j.panicker@ucl.ac.uk

1 Department of Uro-Neurology, The National Hospital for Neurology and Neurosurgery, and UCL Queen Square Institute of Neurology, Faculty of Brain Sciences, University College London,

London WC1N 3BG, UK
Sympathetic innervation of LUT follows complex pathways. Sympathetic preganglionic fibres destined to the LUT originate from T10 to L2 emerges through the ventral roots and descend through three different pathways. One set of preganglionic fibres synapse with postganglionic sympathetic neurons in the superior hypogastric plexus and descend through the inferior hypogastric nerve and enters the inferior hypogastric plexus. Another set of preganglionic fibres descend through the lumbar splanchnic nerves and synapse with postganglionic neurons at the inferior hypogastric plexus. The third set of preganglionic neurons descend through the sympathetic chain and synapse with postganglionic neurons located in the upper sacral ganglia [1]. The postganglionic sympathetic fibres form a delicate network of pelvic nerves and supplies the pelvic viscera. Postganglionic sympathetic fibres leave the lower sacral ganglia and join the sacral and coccygeal nerve roots at the foramina. Sympathetic ganglia become progressively smaller and converge with the parallel sympathetic chain at the ganglion impar (often at the level of the first coccyx) conveying sympathetic efferents to and nociceptive afferents from the perineum and terminal urogenital regions [2]. Sympathetic fibres destined for blood vessels in the leg and foot travel with the tibial nerve, and the sympathetic fibres destined for the pudendal and gluteal arteries and their branches travel with the pudendal and gluteal nerves [1]. 
Parasympathetic fibres originate from the spinal cord S2S4 segments. These preganglionic fibres travel through the cauda equina, exit at S2-S4 sacral foramina and form pelvic splanchnic nerves. These preganglionic parasympathetic fibres pass through inferior hypogastric plexus and synapses with postganglionic neurons located at the vesical plexus, the bladder wall, the region of the bladder neck, the trigone, the prostate, and the proximal urethra [1].

Clinical neurophysiological investigations such as nerve conduction studies, electromyography and evoked potential studies are helpful to assess somatic afferent and efferent nerve pathways. Sympathetic skin response test is helpful to assess sympathetic pathways. To date, there are no electrophysiology tests available to assess parasympathetic pathways.

Electrophysiology tests are well established and widely used in other regions of the body for the assessment of neurogenic damage in nerves and muscles. These tests can be extended to pelvic neurology to assess patients reporting LUT dysfunction. Table 1 summarizes the different tests that are useful to evaluate the damage to the supraconal and conal spinal cord, cauda equina and peripheral nerves resulting in pelvic floor/organ dysfunction. Neurophysiology tests provide objective evidence for nerve damage; however, recordings are influenced by physiological and technical factors and hence results should be interpreted in conjunction with the clinical context and other investigation findings.

\section{Needle Electromyography}

Needle electromyography (EMG) is one of the most useful and widely available tests in clinical neurophysiology. Needle EMG studies are performed using specialized concentric or monopolar needles to record the bioelectrical activity of muscles.

Motor Unit Action Potential (MUAP) analysis helps to differentiate normal muscle pattern from chronically denervated muscle (Fig. 1). MUAP is the sum of all extracellularly recorded potentials of all muscle fibre action potentials within the motor unit [6]. Normative values for external anal sphincter MUAPs are available for interpretation [7, 8]. Longer duration of MUAPs indicates the reinnervation process in the muscle and changes are seen after several weeks or months following an acute nerve injury [9]. The onset of chronic denervation changes depends upon the site and type of nerve injury. Distal and partial nerve lesions show early reinnervation changes within a few weeks whereas lesion at a spinal level can take up to several months to appear.

In acutely denervated muscles, EMG can show abnormal spontaneous activity such as fibrillation and positive sharp wave potentials, which are action potentials of a single denervated muscle fibre. First changes of abnormal spontaneous activity are seen after 3 to 6 weeks of the onset of the nerve injury. To recognize active denervation changes, the muscle should ideally be at rest; the sphincters are always tonically active, and therefore it is challenging to assess for active denervation changes in these muscles due to background muscle noise.

Other spontaneous discharges include Complex Repetitive Discharges (CRD) and Decelerating Bursts (DB), which are fast-firing spontaneous discharges. CRDs are highly symmetric bursts with frequencies ranging between 5 and $100 \mathrm{~Hz}$. Even though CRDs are non-specific findings, their presence usually suggests ongoing chronic denervation and reinnervation in the muscle. CRDs are rarely seen in normal muscles. DBs are bizarre burst discharges superimposed on the normal tonic background motor activity [10]. Frequency and rate of deceleration of these bursts have not been studied and they are recognizable by their characteristic sound. It has been postulated that these discharges occur due to impairment in relaxation of the striated component of sphincter muscles. These non-specific discharges have also been noted in the urethral sphincter of apparently asymptomatic women, however [11]. The innervations of the pelvic floor muscles are derived from multiple myotomes, S2-S4, and if the EMG is abnormal it is not possible to further evaluate which root is specifically damaged (Table 1). EMG testing can be uncomfortable when performed in the perineum and a local anaesthetic may need to be used for some tests.

Despite these limitations, several studies have shown that the EMG test is useful in the evaluation of idiopathic urinary retention [12•*], assessment of suspected pudendal nerve lesions, to aid in the diagnosis of parkinsonian syndromes particularly MSA [13] and evaluation of faecal incontinence [14, $15]$.

\section{Evoked Potentials}

Sensory nerve conduction studies are helpful to assess axonal and myelin function of peripheral sensory nerves. This study can be performed by electrically stimulating the sensory nerve proximally and recording a response from the distal segment of the nerve. However, conventional sensory nerve conduction studies are not usually feasible in the pelvic region as most of the sensory nerve is inaccessible for electrical stimulation. To overcome this, the nerve is stimulated peripherally, and the response is recorded from the somatosensory cortex of the brain using scalp electrodes. The pudendal somatosensory evoked potential study is a well-established test and the most commonly performed evoked potential study in the pelvic region [16] (Fig. 2). Studies have demonstrated the utility of this test in identifying nerve damage in patients presenting with voiding and/or sexual dysfunction [17], predicting the recovery of bladder function in patients with acute spinal cord 
Table 1 Currently performed pelvic neurophysiology tests in clinical practice

\begin{tabular}{|c|c|c|c|c|c|c|c|}
\hline \multirow[t]{2}{*}{ Tests } & \multicolumn{7}{|l|}{ Testing segments } \\
\hline & $\begin{array}{l}\text { Pudendal nerve } \\
\text { sensory } \\
\text { branches }\end{array}$ & $\begin{array}{l}\text { Sacral } \\
\text { sensory } \\
\text { roots }\end{array}$ & $\begin{array}{l}\text { Conus (S2-4 } \\
\text { sacral } \\
\text { segments) }\end{array}$ & $\begin{array}{l}\text { Dorsal column } \\
\text { spinal cord-- } \\
\text { lemniscal } \\
\text { system }\end{array}$ & $\begin{array}{l}\text { Pudendal } \\
\text { nerve } \\
\text { motor } \\
\text { branches }\end{array}$ & $\begin{array}{l}\text { Sacral } \\
\text { motor } \\
\text { roots }\end{array}$ & $\begin{array}{l}\text { Sympathetic } \\
\text { nerves }\end{array}$ \\
\hline Anal sphincter EMG & & & $\mathrm{X}$ & & $\mathrm{x}$ & $\mathrm{X}$ & \\
\hline Urethral sphincter EMG & & & $\mathrm{X}$ & & $\mathrm{x}$ & $\mathrm{X}$ & \\
\hline BCR & $\mathrm{x}$ & $\mathrm{X}$ & $\mathrm{X}$ & & $\mathrm{x}$ & $\mathrm{X}$ & \\
\hline Pudendal SEP & $\mathrm{X}$ & $\mathrm{X}$ & $\mathrm{X}$ & $X$ & & & \\
\hline S2 and S3 DSEP & & $\mathrm{X}$ & $\mathrm{X}$ & $\mathrm{X}$ & & & \\
\hline Tibial SEP & & & & $\mathrm{X}$ & & & \\
\hline SSR & & & & & & & $\mathrm{x}$ \\
\hline $\begin{array}{l}\text { Pudendal Terminal motor } \\
\text { Latency }\end{array}$ & & & & & $\mathrm{x}$ & & \\
\hline $\begin{array}{l}\text { Dorsal penile/clitoral } \\
\text { sensory conductions }\end{array}$ & $\mathrm{X}$ & & & & & & \\
\hline $\begin{array}{l}\text { Pudendal motor evoked } \\
\text { potential [3] }\end{array}$ & & & & & $\mathrm{X}$ & $\mathrm{x}$ & \\
\hline $\begin{array}{l}\text { Spinal root surface electrical } \\
\text { stimulation }[4]\end{array}$ & & & & & & $\mathrm{x}$ & \\
\hline Dartos reflex [5] & & & & & & & $\mathrm{x}$ \\
\hline
\end{tabular}

$B C R$ bulbocavernosus reflex, DSEP dermatomal somatosensory evoked potential, SSR sympathetic skin response

injury [18] and establishing nerve injury in cases presenting with a cauda equina syndrome [19]. However, there are a few technical and anatomical factors that can limit the role of pudendal SEP testing in the diagnosis of pelvic floor disorders. Pudendal SEP cortical amplitudes are low compared to SEPs recorded from mixed nerves such as the tibial nerve (tibial SEP, Fig. 3). This could be due to the absence of Ia large diameter sensory fibres in the dorsal nerve of the penile/clitoris. Due to low cortical potentials, ascertaining amplitude asymmetry can be challenging at times. The pudendal nerve SEP records the response from different sacral dorsal roots, namely S2-S4. Therefore, partial lesions affecting only some of the roots may be missed as the faster conducting noninjured dorsal roots convey the signals to the cortex thus resulting in a SEP with normal latency. Lastly, the stimulating site in males is at the base of the penis and supramaximal stimulation on one side often results in co-stimulation of the nerve on the other side. Due to these limitations, it may not be possible to provide a precise localization when lateralized sacral root injury is suspected which limits the clinical utility of recording pudendal SEPs $[20,21]$.

Measuring Dermatomal Somatosensory Evoked Potentials (DSEP) may help to overcome some of these limitations (Fig. 4). Recording technique for DSEPs is similar to pudendal SEPs, however individual dermatomes are stimulated rather a nerve branch of a sensory nerve. S2 and S3 dermatomal branches arise from the posterior femoral cutaneous nerve, a pure sensory nerve originating in the sacral plexus which supplies the posterior thigh and lower gluteal region [22]. S2 and $\mathrm{S} 3$ dermatomes can be stimulated by placing surface electrodes in the centre of the respective dermatomes. S4 dermatomes can be stimulated with subcutaneous monopolar needle electrodes placed lateral to the mid-anal orifice. DSEPs provide additional information to help localize injury of the sacral roots. Both pudendal and dermatomal SEPs are abnormal following lesions of the sacral roots, whereas the pudendal SEP alone is abnormal following lesions of the pudendal nerve (Table 1). Recording pudendal SEP and DSEPs is helpful in the assessment of sacral root pathology in patients presenting with unexplained urogenital dysfunction, genital numbness or pain and numbness over the gluteal fold [23].

\section{Bulbocavernosus Reflex Study}

Eliciting the bulbocavernosus reflex is one of the most commonly performed bedside clinical tests to assess the integrity of the conus medullaris and cauda equina. The afferent limb of this reflex arc consists of the pudendal nerve and conus medullaris, and the efferent limb consists of the pudendal nerve and its branches - the perineal branch innervating the bulbocavernosus muscle and inferior rectal nerve to the external anal sphincter muscle. Studies have shown that motoneurons in the S2-S4 segments receive input not only from the dorsal nerve of the penis but also from the perineal nerve and sensory nerve endings of the anterior urethra [24]. The 
Fig. 1 Anal sphincter EMG study. Normally appearing MUAPs are seen with amplitudes less than $1000 \mu \mathrm{v}$ and duration less than $10 \mathrm{~ms}$

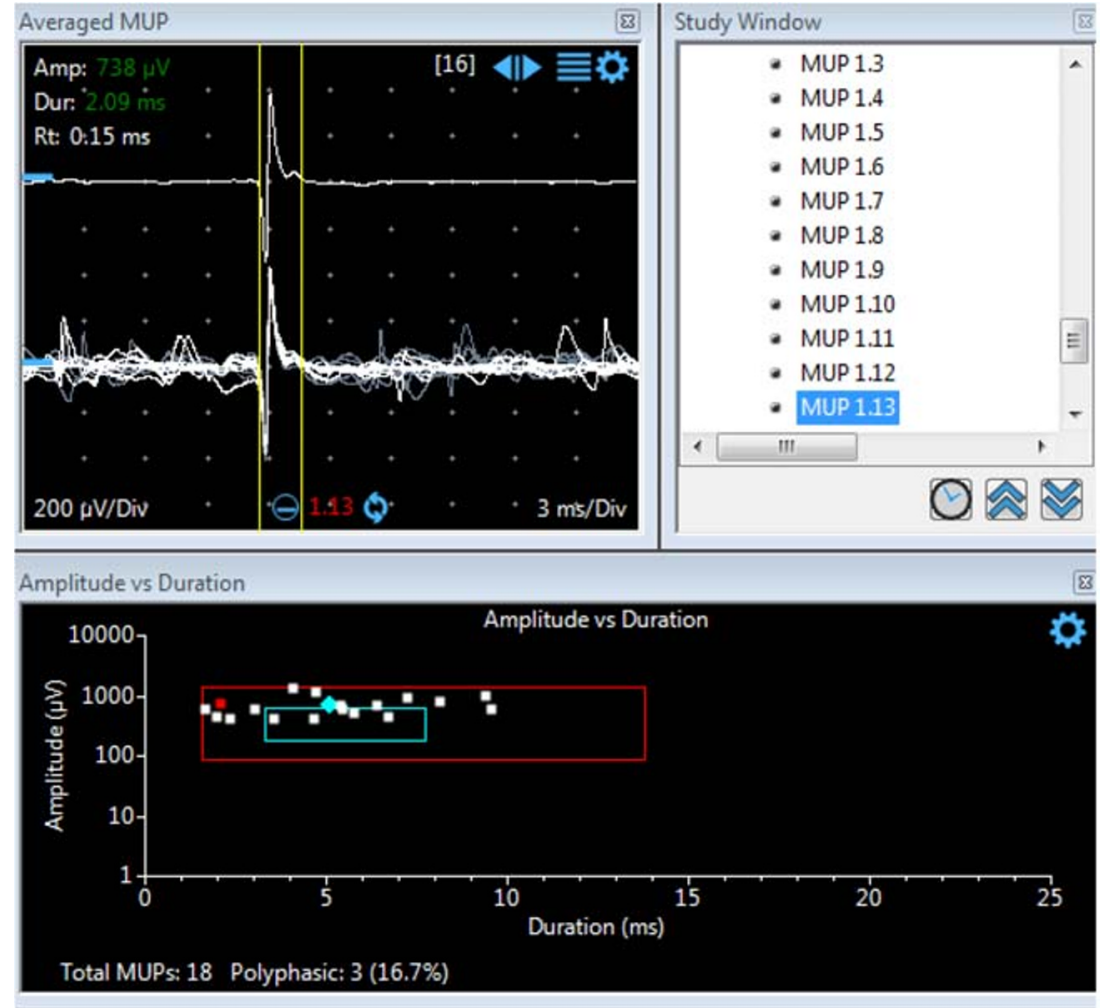

bulbocavernosus reflex (BCR) can be elicited clinically in the external anal sphincter and bulbocavernosus muscle by compressing the glans penis or clitoris sharply in $70-85 \%$ normal subjects [25]. BCR may not be elicitable in unrelaxed individuals and the assessment may need to be repeated if the examiner is not convinced about a response. BCR (Fig. 5) can be recordable following mechanical or electrical stimulations over the penis while recording directly from the bulbocavernosus muscle using a concentric or monopolar needle. Sacral reflex studies such as the BCR test have a greater sensitivity than the clinical elicitation of the reflex [26]. Electrical stimulation over the penis/clitoris will elicit a monosynaptic reflex response (R1) at around $30 \mathrm{~ms}$ and a polysynaptic late response (R2) at around $60 \mathrm{~ms}$. The R1 is a direct response and exhibits no habituation to repeated electrical stimulations. BCR amplitude is dependent on stimulus strength and needle position for the motor endplate. Hence, only a prolonged BCR latency or absent response are considered as abnormal. BCR is an important tool to evaluate the integrity of sensory and motor components of the pudendal nerve (Table 1) and hence needle EMG examination together with BCR study will increase the yield of detecting cauda equina and conus medullaris lesions to over $95 \%$ [27•].
Fig. 2 Pudendal SEP study. Normal " $w$ " shaped waveform: latency is measured in reference to the first downward deflection ( $\mathrm{P} 1$ response) and amplitude is measured as the difference in amplitudes between the $\mathrm{P} 1$ and $\mathrm{N} 1$ responses (N1-P1)

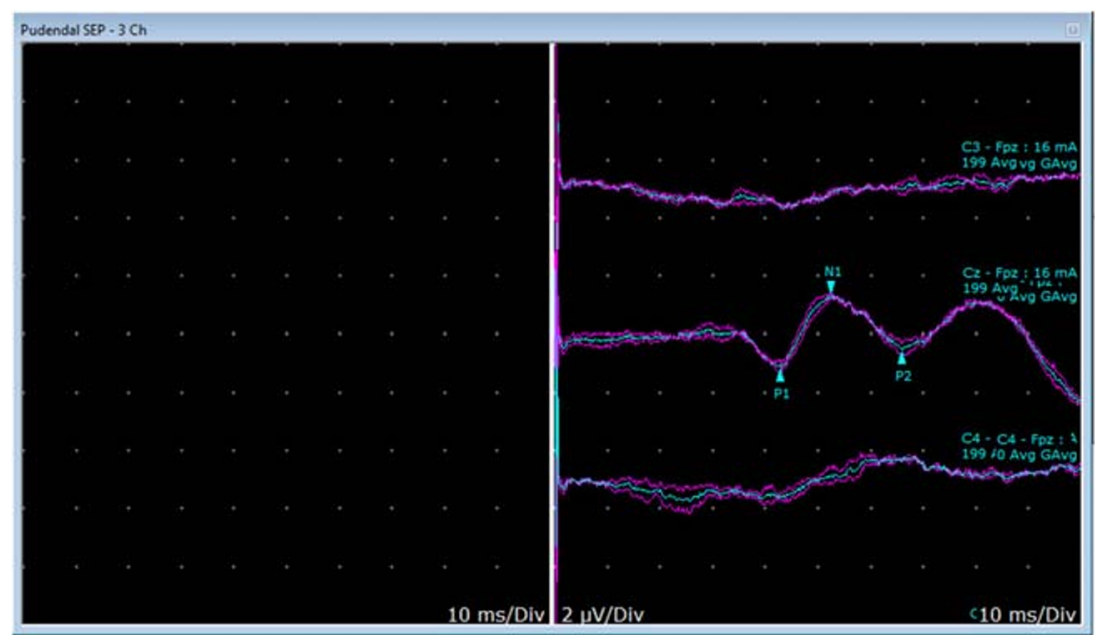


Fig. 3 Tibial SEP study. Normal "w" shaped waveform: latency is measured in reference to the first downward deflection ( $\mathrm{P} 1$ response) and amplitude is measured as the difference in amplitudes between the $\mathrm{P} 1$ and $\mathrm{N} 1$ responses $(\mathrm{N} 1-\mathrm{P} 1)$

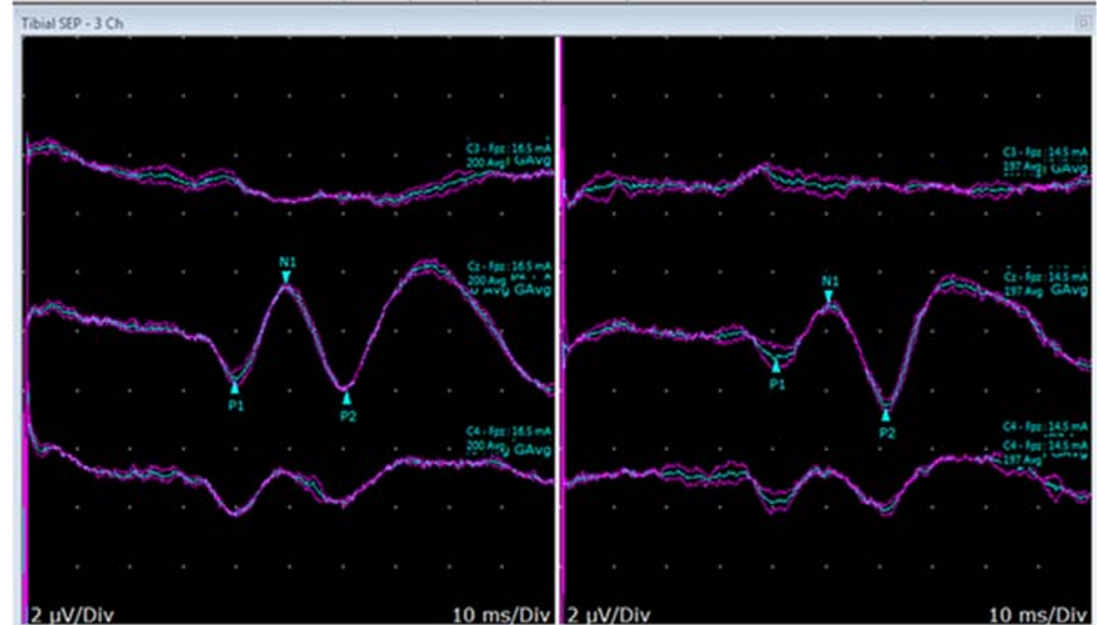

\section{Sympathetic Skin Response}

Sympathetic Skin Response (SSR) assesses the functional integrity of the cutaneous efferent sympathetic pathways. Eccrine sweat glands in the hands, feet and perineum are innervated by unmyelinated $\mathrm{C}$-fibres of the sympathetic autonomic nervous system. The potential difference across the skin will provide an objective assessment for a sympathetic nervous system function (Table 1).

The afferent limb of the SSR includes myelinated somatosensory pathways to the brainstem and the efferent limb of the reflex consists mainly of unmyelinated C-fibres through the intermediolateral column, hypogastric plexus, ultimately innervating the LUT, genitalia and skin. The reflex is therefore widely distributed across a complex polysynaptic pathway and it is therefore often difficult to localize the lesion when the SSR is absent. However, simultaneous recording of the SSR from hands, perineum and the feet after stimulating two different nerves helps to localize the lesion. Absence of SSR in the perineum, whereas recordable in the upper and lower limbs, suggests a possible lesion at the T10-L2 level [28], whereas the absence of both the perineal and lower limb SSR could suggest a lesion between T4-T9 segments [29], or possibly a neuropathy involving small nerve fibres. Absence of the lower limb SSR alone could suggest an early stage of neuropathy involving small nerve fibres [30]. Studies have shown a correlation between the absence of SSR and bladder neck dysfunction in spinal cord lesions levels above the T6 level [31]. Sympathetic fibres play a major role in the neural control of erection and ejaculation besides innervating the perineal sweat glands. Hence, recording the SSR in the perineal area provides useful information when evaluating a neurological cause for erectile and ejaculatory dysfunction [32].

The distribution of eccrine glands is not uniform over the body and their density is greatest over the palms and soles [33] and more thinly distributed over the thighs and back. SSR response recorded from the perineal skin is therefore of much smaller amplitude compared to palms and soles. In addition, SSR responses are influenced by a variety of reasons such as
Fig. 4 S3 dermatomal SEP study. Normal "w" shaped waveform: latency is measured in reference to the first downward deflection ( $\mathrm{P} 1$ response) and amplitude is measured as the difference in amplitudes between the $\mathrm{P} 1$ and N1 responses (N1-P1)

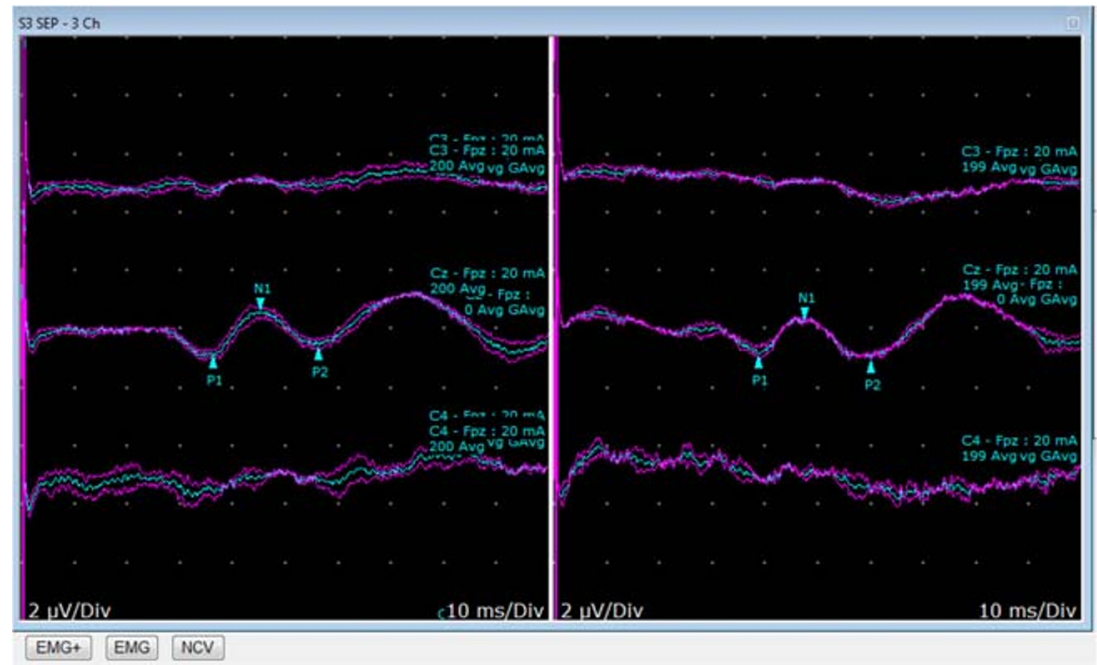


Fig. 5 Bulbocavernosus reflex study. The response is recorded from the bulbospongiosus following repeated electrical stimulation of the dorsal penile nerve. The latency of the response in this case is $33.4 \mathrm{~ms}$

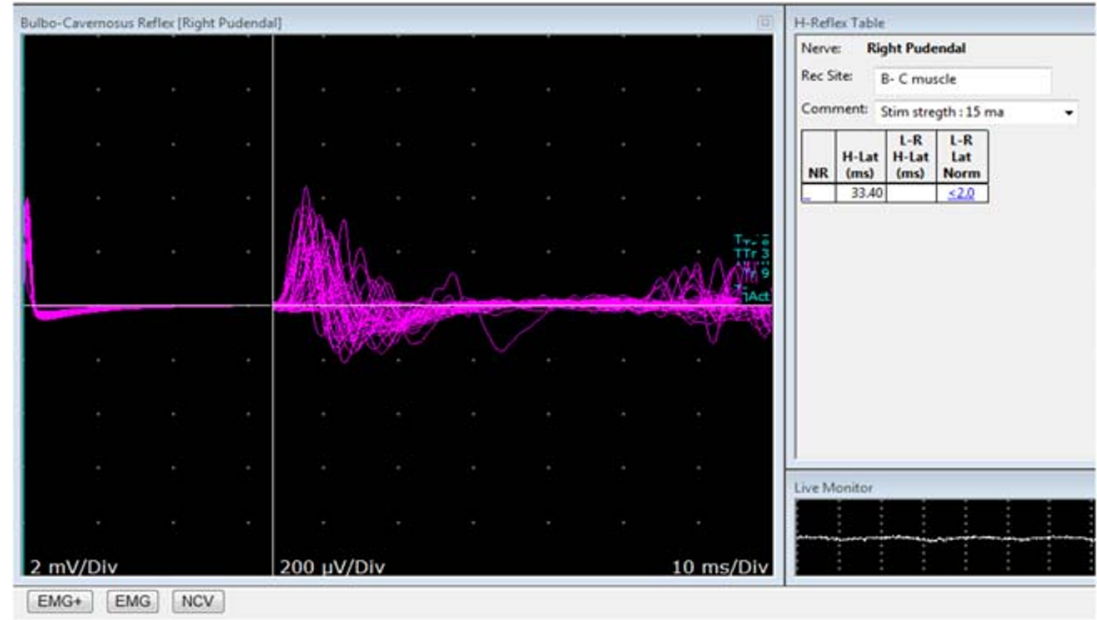

temperature, stimulus strength, habituation and patient relaxation. Hence, physiological and environmental factors should be taken into consideration when interpreting the SSR. Due to a high degree of variability in SSR amplitude, the presence of a clear SSR response is enough to be considered a normal study.

\section{Other Tests}

Pudendal nerve terminal motor latency (PNTML) is a wellestablished test to assess terminal motor branches of the pudendal nerve (Table 1). Even though normative data has been published, the test is less widely performed nowadays because of different reasons. Technical difficulties such as short distance between stimulation and recording sites, high variability in the onset latency and poor patient tolerance to high-strength electrical stimulation limits this test for wider usage. Moreover, the test provides information only about a short segment of the distal pudendal nerve whereas pudendal nerve compression is usually more proximally sited such as in the Alcock's canal. PNTML is operator dependent and needs to be performed skillfully. Hence, the reliability and clinical relevance of PNTML is debatable [34, 35••].

Dorsal penile nerve sensory conduction study is a useful but under-performed study to assess peripheral pudendal (dorsal penile nerve) sensory nerve functions (Table 1) [36]. Challenges encountered when performing this test include high penile skin impedance and short penile length.

Dartox Reflex(DR) is a sympathetic response recorded from scrotal vermicular motion (Table 1) [5]. DR can be recorded with surface skin electrodes over the scrotum following median nerve stimulation. DRs add additional information when testing sympathetic autonomic fibres and genitofemoral nerve.

\section{Indications for Pelvic Neurophysiology Testing in Clinical Practice}

There are several situations in neurourology clinical practice where pelvic neurophysiology testing is useful in the diagnostic formulation:

Fig. 6 Applications of pelvic neurophysiology testing in patients with voiding dysfunction. a-e Pelvic neurophysiology study in a 37 year old male (height $170 \mathrm{~cm}$ ), reporting urinary urgency and incontinence episodes occurring 3-4 times a week, occasional bowel urgency and impaired sensation perianally and the shaft of the penis for around 10 years. MRI shows a suspicious lesion in the conus medullaris of uncertain significance. a Tibial SEP, stimulation frequency: $3.1 \mathrm{~Hz}$, stimulation strength: 20mA; Latency Right: 44.5 ms \& Left: 43.8 ms; Amplitude Right: $3.3 \mu \mathrm{v} \&$ Left:1.9 $\mu$ v. b S2 Dermatomal SEP, stimulation frequency: $3.1 \mathrm{~Hz}$, stimulation strength: $25 \mathrm{~mA}$; Latency Right: $41.6 \mathrm{~ms}$ \& Left: Absent; Amplitude Right: $0.4 \mu \mathrm{v}$. c S3 Dermatomal SEP, stimulation frequency: $3.1 \mathrm{~Hz}$, stimulation strength: $25 \mathrm{~mA}$; Latency Right: $45.0 \mathrm{~ms}$ \& Left: inconsistent response; Amplitude Right: $0.37 \mu v$. d Pudendal SEP, stimulation frequency: $3.1 \mathrm{~Hz}$, stimulation strength: $39 \mathrm{~mA}$; Latency: $47.5 \mathrm{~ms}$, Very low amplitude $\sim 0.1 \mu \mathrm{v}$. e $\mathrm{BCR}$ responses are present but inconsistent on the right side with latency $35.1 \mathrm{~ms}$. Absent response on the left side. Conclusion: The neurophysiology abnormalities are consistent with a lesion affecting the sacral somatic afferent and efferent (anal sphincter EMG was also abnormal, not shown) innervation. The suspicious conus lesion seen in MRI is therefore significant. f Concentric needle EMG of the external anal sphincter in a 54-year-old gentleman presenting with voiding difficulties and incontinence on the background of a recent onset parkinsonism syndrome. Duration $35.9 \mathrm{~ms}$, which is prolonged, and suggests chronic reinnervation. The mean duration of MUPs in this study was abnormally prolonged at $16 \mathrm{~ms}$ (normal $<10 \mathrm{~ms}$ ). The EMG abnormalities are consistent with a diagnosis of multiple system atrophy (gain $50 \mu \mathrm{v} / \mathrm{Div}$ and sweep speed $5 \mathrm{~ms} / \mathrm{Div}$ ). g Concentric needle EMG of the urethral sphincter in a young woman presenting with urinary retention demonstrating abnormal decelerating burst (gain $200 \mu \mathrm{v} / \mathrm{Div}$ and sweep speed $10 \mathrm{~ms} / \mathrm{Div}$ ). h Concentric needle EMG of the urethral sphincter in a young woman presenting with urinary retention demonstrating complex repetitive discharges (gain $50 \mu \mathrm{v} / \mathrm{Div}$ and sweep speed $15 \mathrm{~ms} / \mathrm{Div}$ ) 


\section{Patients Reporting LUT Symptoms on the Background of a Suspected Parkinsonian Syndrome}

Multiple System Atrophy (MSA) is a neurodegenerative disorder and this synucleinopathy is characterized by abnormal accumulation of glial cytoplasmic inclusions (GCIs) consisting of aggregates of $\alpha$-synuclein protein in the oligodendrocytes. MSA is characterized by autonomic failure and neurological signs, and patients present with urogenital symptoms, bowel dysfunction, orthostatic hypotension, parkinsonism and cerebellar ataxia. The condition may, however, be mistaken for Parkinson's disease (PD), particularly in its early stages, and the distinction is critical as MSA is poorly responsive to antiparkinsonian treatment and has a more rapid disease progression compared to PD, being fatal within 610 years of the onset of symptoms. Patients with MSA often present early with significant LUT and sexual dysfunction, even prior to the onset of neurological complaints, and patients may present to a Urologist initially. Urinary incontinence is often severe and urinary retention presents early and generally progresses with advancing disease [37••]. Neurons in the lower spinal cord such as the Onuf's nucleus are particularly susceptible to degeneration in this condition
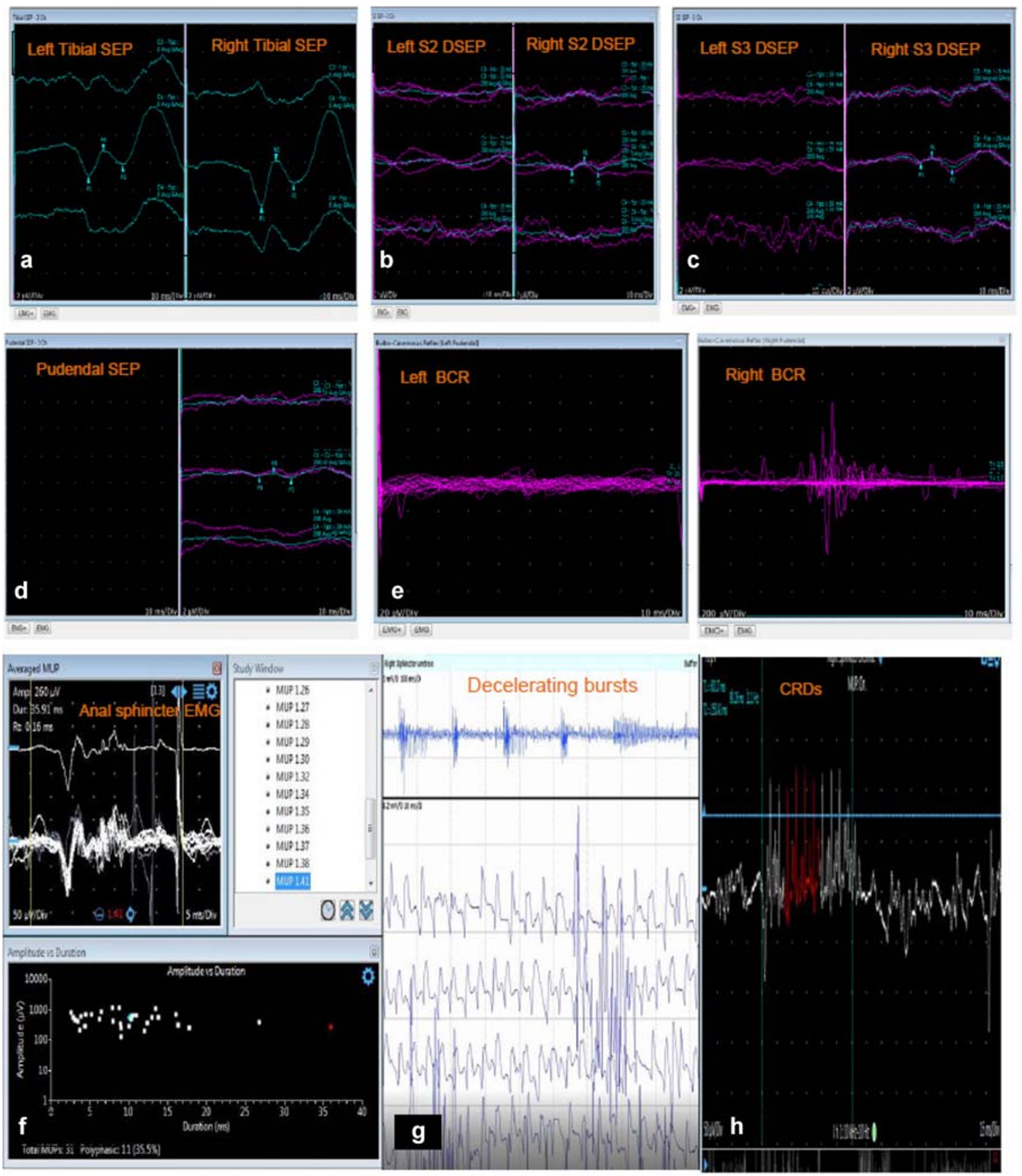
$[38 \bullet \bullet]$ and therefore the anal sphincter EMG $[39,40 \bullet \cdot$ and bulbocavernosus reflex $[41 \bullet \bullet$ are useful tests to detect damage, and therefore help to differentiate MSA from PD. The sensitivity and specificity of anal sphincter EMG in differentiating MSA from PD are 35 and $90 \%$, respectively [42] whereas, for BCR, these are 24 and $91-94 \%$, respectively [43•]. The value of sphincter EMG in the differential diagnosis of Parkinsonism has been debated over the years. A falsenegative result may occur if the neurodegenerative process is limited and yet to affect the sacral spinal cord (Onuf's nucleus). A false-negative result can also arise from errors in MUAP analysis. Automated MUAP analysis by the machine tends to ignore long-duration polyphasic potentials with satellite potentials and rather, analyses the individual components as separate short-duration MUAPs. Hence, it is advisable for the operator to measure MUAPs manually when MSA is suspected. Abnormal EMG findings may be seen in other neurodegenerative conditions such as long-standing Parkinson's disease, Progressive supranuclear palsy, Dementia with Lewy Bodies and Spinocerebellar ataxia type3, following cauda equina injury, and following damage to the sphincter muscle such as haemorrhoid surgery and pelvic floor tears of traumatic childbirth. Hence, the EMG result should be interpreted in the appropriate clinical context. Nevertheless, a highly abnormal result in a patient with mild Parkinsonism is of value in establishing a diagnosis of probable MSA [13], particularly in the first 5 years of neurological symptoms [39]. This differentiation between MSA and PD is important not only for the Neurologist, but also for the Urologist, as incontinence rates are greater in men with MSA following prostatectomy, and should, therefore, be avoided [44].

\section{Young Woman Presenting with Urinary Retention}

Urinary retention is uncommon in women, and in situations where the routine neurological and urological assessment fails to identify a cause, a primary disorder of urethral sphincter relaxation (Fowler's Syndrome) should be investigated. The urethral pressure profile is abnormally elevated, often in excess of $100 \mathrm{cmH} 2 \mathrm{O}$, and abnormalities can be found in the urethral sphincter EMG, namely decelerating bursts, a signal somewhat like myotonia (Fig. 6g), and complex repetitive discharges (CRDs) (Fig. 6h). EMG changes have been shown to correlate with a pulsatile UPP trace [45••]. It has been proposed that this abnormal spontaneous activity results in impairment of relaxation of the urethral sphincter, which may cause urinary retention in some women and obstructed voiding in others [10]. CRDs have been reported in apparently asymptomatic women $[11,46]$ and therefore abnormal EMG findings should be interpreted considering the clinical context.
Sacral neuromodulation is an effective treatment for urinary retention, and a favourable outcome has been reported in women with an abnormal urethral sphincter EMG [47].

\section{Patients with Cauda Equina/Conus Medullaris Lesions Reporting Urogenital Dysfunction}

Damage to the pelvic splanchnic innervation following cauda equina and conus medullaris lesions results in LUT, bowel and sexual dysfunction, and this is a common referral to centres with a specialist interest in Neurourology. The sacral somatic nerves are also damaged and denervation changes can be seen as early as 2 to 3 weeks after onset of disease in EMG of the pelvic floor muscles. Neurophysiology testing is useful to assess ongoing somatic nerve damage by the presence of spontaneous denervation activity in the EMG, whereas ongoing chronic denervation or recovery of somatic nerves from the damage can be assessed with quantitative EMG. Chronic denervation changes in the EMG are characterized by reduced interference pattern and polyphasic MUAPs with prolonged duration and abnormally increased amplitudes $(>1 \mathrm{mV})$. Studies have shown a correlation between neurophysiological changes following cauda equina injury with the severity of sexual dysfunction [48]. Bulbocavernosus reflex responses are also useful to evaluate acute and subacute compression of the sacral somatic motor and sensory nerves following cauda equina or conus injury. Absence of the BCR during the acute stage of injury has been shown to prognosticate poorer recovery of bladder and sexual functions, whereas the presence of a BCR response with either normal or prolonged latency has been associated with recovery in bowel, bladder and sexual functions $\left[49,50^{\bullet}\right]$. In situations where the clinical scenario mimics a cauda equina presentation in terms of back pain and urogenital and bowel dysfunction however the MRI scan does not reveal significant abnormalities, pelvic neurophysiological tests are useful to evaluate evidence for sacral root dysfunction that could account for symptoms.

\section{Patients Presenting with Unexplained Urogenital Complaints where the Abnormality Seen in Spine MRI Is of Uncertain Relevance}

During the course of investigations of a patient presenting with urogenital complaints of uncertain cause, an MRI lumbosacral spine scan is often requested and it is not unusual for imaging to reveal findings of uncertain clinical significance, such as degenerative disc disease, lumbar canal stenosis, Tarlov (perineural) cyst, thickened filum terminale and inflammatory/ischemic lesion in the conus. In such cases, pelvic neurophysiology tests, e.g. somatosensory evoked 
potentials, quantitative EMG and sacral reflex studies, are useful to establish whether the finding seen in MRI is significantly affecting the sacral somatic innervation [51••] (Fig. 6). L5-S1 cutaneous afferents contribute to tibial SEP responses [52], and therefore a lesion of the conus (or cauda) would be suspected when the tibial SEP is normal and pudendal, S2 or S3 dermatomal SEP responses, BCR and/or anal sphincter EMG tests are abnormal [53•0]. Moreover, these tests can help localize the lesion and distinguish peripheral from central lesions, and afferent from efferent pathway lesions [54]. Neurophysiology tests are useful from a neurological perspective to identify potential candidates for surgical management of conus/cauda lesions [23]. In situations where sacral neuromodulation is being considered for managing LUT dysfunction, neurophysiology tests might be helpful to assess the integrity of the sacral roots.

\section{Concluding Remarks}

Pelvic neurophysiological tests provide objective evidence for the involvement of the sacral roots when evaluating patients with unexplained voiding dysfunction. These tests are particularly helpful in evaluating the sacral afferent and efferent somatic pathways. SSR and Dartos Reflex are helpful in the assessment of sympathetic innervation in the pelvic region. Tests need to be performed with care, and the results should be interpreted in the relevant clinical context in the setting of a multidisciplinary team.

Acknowledgements JNP is supported in part by funding from the United Kingdom's Department of Health NIHR Biomedical Research Centres funding scheme. PM receives funding via Health Education England for Higher Specialist Scientist Training.

\section{Compliance with Ethical Standards}

Conflict of Interest The authors declare that they have no conflict of interest.

Human and Animal Rights and Informed Consent This article does not contain any studies with human or animal subjects performed by any of the authors.

Open Access This article is licensed under a Creative Commons Attribution 4.0 International License, which permits use, sharing, adaptation, distribution and reproduction in any medium or format, as long as you give appropriate credit to the original author(s) and the source, provide a link to the Creative Commons licence, and indicate if changes were made. The images or other third party material in this article are included in the article's Creative Commons licence, unless indicated otherwise in a credit line to the material. If material is not included in the article's Creative Commons licence and your intended use is not permitted by statutory regulation or exceeds the permitted use, you will need to obtain permission directly from the copyright holder. To view a copy of this licence, visit http://creativecommons.org/licenses/by/4.0/.

\section{References}

Papers of particular interest, published recently, have been highlighted as:

- Of importance

• Of major importance

1. Darby SA. Chapter 10 - Neuroanatomy of the Autonomic Nervous System. In: Cramer GD, Darby SA, editors. Clinical Anatomy of the Spine, Spinal Cord, and Ans (Third Edition). Saint Louis: Mosby; 2014. p. 413-507.

2. Standring S, Ellis H, Healy J, Johnson D, Williams A, Collins P, et al. Gray's anatomy: the anatomical basis of clinical practice. Am J Neuroradiol. 2005;26(10):2703.

3. Brostrom S, Jennum P, Lose G. Motor evoked potentials from the striated urethral sphincter: a comparison of concentric needle and surface electrodes. Neurourol Urodyn. 2003;22(2):123-9.

4. Pelliccioni G, Scarpino O. External anal sphincter responses after S3 spinal root surface electrical stimulation. Neurourol Urodyn. 2006;25(7):788-91.

5. Yilmaz U, Yang CC, Berger RE. Dartos reflex: a sympathetically mediated scrotal reflex. Muscle Nerve. 2006;33(3):363-8.

6. Nandedkar SD, Barkhaus PE. Quantitative EMG analysis. In: Neuromuscular disorders in clinical practice. Berlin: Springer; 2014. p. 165-99.

7. Podnar S, Vodušek DB, Stålberg E. Standardization of anal sphincter electromyography: normative data. Clin Neurophysiol. 2000;111(12):2200-7.

8. Zhao L, Du H, Li B, Wu S, Lin N. The impact of physiological features on external anal sphincter electromyography. J Neurol Neurophysiol. 2014;5(227):2.

9. Daube JR, Rubin DI. Needle electromyography. Muscle Nerve. 2009;39(2):244-70.

10. Fowler CJ, Kirby RS. Abnormal electromyographic activity (decelerating burst and complex repetitive discharges) in the striated muscle of the urethral sphincter in 5 women with persisting urinary retention. Br J Urol. 1985;57(1):67-70.

11. Tawadros C, Burnett K, Derbyshire LF, Tawadros T, Clarke NW, Betts CD. External urethral sphincter electromyography in asymptomatic women and the influence of the menstrual cycle. BJU Int. 2015;116(3):423-31.

12.• Panicker JN, Pakzad M, Fowler CJ. Fowler's syndrome: a primary disorder of urethral sphincter relaxation. Obstet Gynaecol. 2018;20(2):95-100 Neuromodulation and sphincter Botox injections have shown to be effective in managing urinary retention.

13. Vodušek DB. Sphincter EMG and differential diagnosis of multiple system atrophy. Mov Disord. 2001;16(4):600-7.

14. Cheong D, Vaccaro C, Salanga V, Wexner S, Phillips R, Hanson $\mathrm{M}$, et al. Electrodiagnostic evaluation of fecal incontinence. Muscle Nerve. 1995;18:612-9.

15. Vernava AM, Longo WE, Daniel GL. Pudendal neuropathy and the importance of EMG evaluation of fecal incontinence. Dis Colon Rectum. 1993;36(1):23-7.

16. Yeh M, Yamada T, Kimura J. Chapter 20 Applications of SSEP recordings in the evaluation of the peripheral nervous system. In: Kimura J, editor. Handbook of Clinical Neurophysiology, vol. 7. Amsterdam: Elsevier; 2006. p. 443-66.

17. Klausner AP, Batra AK. Pudendal nerve somatosensory evoked potentials in patients with voiding and/or erectile dysfunction: correlating test results with clinical findings. J Urol. 1996;156(4):1425-7.

18. Curt A, Rodic B, Schurch B, Dietz V. Recovery of bladder function in patients with acute spinal cord injury: significance of ASIA scores and somatosensory evoked potentials. Spinal Cord. 1997;35:368-73. 
19. Niu X, Wang X, Ni P, Huang H, Zhang Y, Lin Y, et al. Bulbocavernosus reflex and pudendal nerve somatosensory evoked potential are valuable for the diagnosis of cauda equina syndrome in male patients. Int J Clin Exp Med. 2015;8(1):1162-7.

20. Delodovici ML, Fowler CJ. Clinical value of the pudendal somatosensory evoked potential. Electroencephalogr Clin Neurophysiol/ Evoked Potentials Sect. 1995;96(6):509-15.

21. Rapidi CA, Karandreas N, Katsifotis C, Benroubi M, Petropoulou $\mathrm{K}$, Theodorou C. A combined urodynamic and electrophysiological study of diabetic cystopathy. Neurourol Urodyn. 2006;25(1):32-8.

22. Moore KL. Clinically oriented anatomy. 3rd ed. Baltimore: Williams \& Wilkins; 1992. xiii. p. 917.

23. Dikmen PY, Emre OA. Diagnostic use of dermatomal somatosensory-evoked potentials in spinal disorders: case series. J Spinal Cord Med. 2013;36(6):672-8.

24. Yang CC, Bradley WE. Somatic innervation of the human bulbocavernosus muscle. Clin Neurophysiol. 1999;110(3):412-8.

25. Rushworth G. Diagnostic value of the electromyographic study of reflex activity in man. Electroencephalogr Clin Neurophysiol. 1967;25:65-73.

26. Vodušek DB. Electromyogram, evoked sensory and motor potentials in neurourology. Neurophysiol Clin. 1997;27(3):204-10.

27. Bianchi F, Squintani GM, Osio M, Morini A, Bana C, Ardolino G, et al. Neurophysiology of the pelvic floor in clinical practice: a systematic literature review. Funct Neurol. 2017;22(4):173-93 Continues to confirm the utility of neurophysiology tests in Uro-Neurology.

28. Rodic B, Curt A, Dietz V, Schurch B. Bladder neck incompetence in patients with spinal cord injury: significance of sympathetic skin response. J Urol. 2000;163(4):1223-7.

29. Opsomer R-J, Boccasena P, Traversa R, Rossini P. Sympathetic skin responses from the limbs and the genitalia: normative study and contribution to the evaluation of neurourological disorders. Electroencephalogr Clin Neurophysiol/Electromyogr Mot Control. 1996;101(1):25-31.

30. Stewart JD, Low PA, Fealey RD. Distal small fiber neuropathy: results of tests of sweating and autonomic cardiovascular reflexes. Muscle Nerve. 1992;15(6):661-5.

31. Curt A, Nitsche B, Rodic B, Schurch B, Dietz V. Assessment of autonomic dysreflexia in patients with spinal cord injury. J Neurol Neurosurg Psychiatry. 1997;62(5):473-7.

32. Ertekin C, Ertekin N, Mutlu S, Almis S, Akcam A. Skin potentials (SP) recorded from the extremities and genital regions in normal and impotent subjects. Acta Neurol Scand. 1987;76(1):28-36.

33. Dole VP, Thaysen JH. Variation in the functional power of human sweat glands. J Exp Med. 1953;98(2):129-44.

34. Cooper EA, De-Loyde KJ, Young CJ, Shepherd HL, Wright C. Pudendal nerve testing does not contribute to surgical decision making following anorectal testing in patients with faecal incontinence. Int J Color Dis. 2016;31(8):1437-42.

35.• Saraidaridis JT, Molina G, Savit LR, Milch H, Mei T, Chin S, et al. Pudendal nerve terminal motor latency testing does not provide useful information in guiding therapy for fecal incontinence. Int $\mathrm{J}$ Color Dis. 2018;33(3):305-10 PNTML testing may not be relevant to current therapeutic algorithms for fecal incontinence.

36. Clawson DR, Cardenas DD. Dorsal nerve of the penis nerve conduction velocity: a new technique. Muscle Nerve. 1991;14(9):845-9.

37.• Sakakibara R, Panicker J, Simeoni S, Uchiyama T, Yamamoto T, Tateno F, et al. Bladder dysfunction as the initial presentation of multiple system atrophy: a prospective cohort study. Clin Auton Res. 2019;29(6):627-31 Bladder dysfunction as the sole initial manifestation in $18.2 \%$ of patients presented with MSA.

38.• Panicker JN, Simeoni S, Miki Y, Batla A, Iodice V, Holton JL, et al. Early presentation of urinary retention in multiple system atrophy: can the disease begin in the sacral spinal cord? J Neurol. 2020;267(3):659-64 Patients presenting with urinary retention and mild neurological features would be an ideal group for experimental trials evaluating neuroprotection in MSA.

39. Paviour DC, Williams D, Fowler CJ, Quinn NP, Lees AJ. Is sphincter electromyography a helpful investigation in the diagnosis of multiple system atrophy? A retrospective study with pathological diagnosis. Move Disord. 2005;20(11):1425-30.

40.• Stankovic I, Quinn N, Vignatelli L, Antonini A, Berg D, Coon E, et al. A critique of the second consensus criteria for multiple system atrophy. Mov Disord. 2019;34(7):975-84 A validation exercise on the novel criteria in a prospective clinicopathological study is needed to determine their diagnostic accuracy of MSA.

41.• Cai ZY, Niu XT, Pan J, Ni PQ, Wang X, Shao B. The value of the bulbocavernosus reflex and pudendal nerve somatosensory evoked potentials in distinguishing between multiple system atrophy and Parkinson's disease at an early stage. Acta Neurol Scand. 2017;136(3):195-203 Prolonged BCR latency may be valuable for distinguishing between MSA and PD in the early stages.

42. Yamamoto T, Sakakibara R, Uchiyama T, Yamaguchi C, Nomura $\mathrm{F}$, Ito $\mathrm{T}$, et al. Receiver operating characteristic analysis of sphincter electromyography for parkinsonian syndrome. Neurourol Urodyn. 2012;31(7):1128-34.

43. Huang H-j, Zhu X-y, Wang X, Wang Z-y, Zhang W-1, Chen B-c, et al. The Bulbocavernosus reflex in the differential diagnosis of multiple system atrophy with predominant parkinsonism and Parkinson's disease. Front Neurol. 2018;8:697 BCR may be used to discriminate between MSA-P and PD in some cases.

44. Sakakibara R, Panicker J, Finazzi-Agro E, Iacovelli V, Bruschini H. The Parkinson's Disease Subcomittee TNPCiTICS. A guideline for the management of bladder dysfunction in Parkinson's disease and other gait disorders. Neurourol Urodyn. 2016;35(5):551-63.

45.• Sihra N, Malde S, Panicker J, Kightley R, Solomon E, Hamid R, et al. Does the appearance of the urethral pressure profile trace correlate with the sphincter EMG findings in women with voiding dysfunction? Neurourol Urodyn. 2018;37(2):751-7 There is no obvious correlation between a pulsatile UPP trace and a reported "catching" sensation on catheterization.

46. Ramm O, Mueller ER, Brubaker L, Lowenstein L, Kenton K. Complex repetitive discharges - a feature of the urethral continence mechanism or a pathological finding? J Urol. 2012;187(6):2140-3.

47. De Ridder D, Ost D, Bruyninckx F. The presence of Fowler's syndrome predicts successful long-term outcome of sacral nerve stimulation in women with urinary retention. Eur Urol. 2007;51(1):229-34.

48. Podnar S, Oblak C, Vodušek DB. Sexual function in men with cauda equina lesions: a clinical and electromyographic study. J Neurol Neurosurg Psychiatry. 2002;73(6):715-20.

49. Lavoisier P, Proulx J, Courtois F, Carufel FD. Bulbocavernosus reflex: its validity as a diagnostic test of neurogenic impotence. $\mathrm{J}$ Urol. 1989;141(2):311-4.

50. Previnaire JG. The importance of the bulbocavernosus reflex. Spinal Cord Ser Cases. 2018;4(1):2 BCR is complementary to the voluntary contraction of the external anal sphincter and should be added to ISNCSCI and ISAFSCI classifications.

51.• Hulens M, Rasschaert R, Bruyninckx F, Dankaerts W, Stalmans I, De Mulder P, et al. Symptomatic Tarlov cysts are often overlooked: ten reasons why - a narrative review. Eur Spine J. 2019:1-12 Symptomatic Tarlov cysts are underdiagnosed, mostly due to persistent misconceptions and biases.

52. Katifi HA, Sedgwick EM. Somatosensory evoked potentials from posterior tibial nerve and lumbosacral dermatomes. Electroencephalography and Clinical Neurophysiology/Evoked Potentials Section. 1986;65(4):249-59.

53.• Li V, Malladi P, Simeoni S, Pakzad M, Everett R, Chanjira S, Leite MI, Palace J, Panicker JN. A clinico-neurophysiological study of urogenital dysfunction in MOG-antibody transverse myelitis. Neurology. 2020. Urinary retention in the absence of other neurological symptoms can be the first presentation of TM in 
MOG-Ab disease and recovery and the length of indwelling catheteristion is likely to be influenced by the presence of lesions of the conus. The paper discusses the neurophysiology findings associated with conus lesions.

54. Ziemann U, Reimers C. Anal sphincter electromyography, bulbocavernosus reflex and pudendal somatosensory evoked potentials in diagnosis of neurogenic lumbosacral lesions with disorders of bladder and large intestine emptying and erectile dysfunction. Nervenarzt. 1996;67(2):140-6.

Publisher's Note Springer Nature remains neutral with regard to jurisdictional claims in published maps and institutional affiliations. 